\title{
The Role of Compensation in Chronic Pain: Analysis Using a New Method of Scoring the McGill Pain Questionnaire
}

\author{
Ronald Melzack ${ }^{1}$, Joel Katz and Mary Ellen Jeans ${ }^{2}$ \\ Department of Psychology, McGill University, Montreal, Que. H3A IB1 (Canada)
}

\section{Summary}

Patients who receive worker's compensation or are awaiting litigation after an accident have long been regarded as neurotics or malingerers who are exaggerating their pain for financial gain. However, there is a growing body of evidence that patients who receive worker's compensation are no different from patients who do not. In particular, a recent study found no differences between compensation and non-compensation patients based on pain scores obtained with the McGill Pain Questionnaire (MPQ). Since the MPQ is usually scored by using rank values rather than more complex scale values, the negative finding might be attributable to the loss of information by using rank values. Consequently, a simple technique was developed to convert rank values to weighted-rank values which are equivalent to scale values. A study of 145 patients suffering low-back and musculoskeletal pain revealed that compensation and non-compensation patients had virtually identical pain scores and pain descriptor patterns. They were also similar on the MMPI pain triad (depression, hysteria, hypochondriasis) and on several other personal variables that were examined. The only differences were significantly lower affective or evaluative MPQ scores and fewer visits to health professionals by compensation patients compared to non-compensation patients. These results suggest that the financial security provided by compensation decreases anxiety, which is reflected in the lower affective or evaluative ratings but not the sensory or total MPQ scores. Compensation patients, contrary to traditional opinion, appear not to differ from

\footnotetext{
1 Address correspondence to: Dr. Ronald Melzack, Department of Psychology, McGill University, 1205 Docteur Penfield Avenue, Montreal, Que. H3A 1B1. Canada.

2 School of Nursing, McGill University.
} 
people who do not receive compensation. Accidents which produce injury and pain should be considered as potentially psychologically traumatic as well as conducive to the development of subtle physiological changes such as trigger points. Patients on compensation or awaiting litigation deserve the same concern and compassion as all other patients who suffer chronic pain.

\section{Introduction}

The 'worker's compensation case' has become the pariah among pain patients. Most people who suffer chronic pain are accorded sympathy and the best available palliative care by health professionals. Patients on compensation or awaiting litigation. however, are frequently regarded as neurotics or malingerers - people trying to live off the avails of others by deviously faking their pain. The prevailing view is reflected by the following definition: 'A compensation neurosis is a state of mind, born out of fear, kept alive by avarice, stimulated by lawyers, and cured by a verdict' [5]. The implications of a voluminous literature on "compensation neurosis" $[17.18,21.22]$ are that patients who suffer disability and pain after an injury and await litigation for compensation are (1) exaggerating their pain. (2) suffering psychopathology in terms of excessive anxiety, depression and neuroticism, and (3) planning to return to work promptly after receiving the verdict of their litigation case. Recent studies indicate that there is no evidence to support these assumptions.

Mendelson [12.13]. Pelz and Merskey [14] and Leavitt et al. [6] have recently shown that low-back pain patients do not fall neatly into separate 'worker's compensation' and 'non-compensation' categories. Mendelson [13] reports that compensation and non-compensation patients have virtually identical pain scores on all dimensions of the McGill Pain Questionnaire. Nor is there any evidence that compensation cases show higher levels of psychopathology than non-compensation cases [13,14]. Both groups show higher levels of psychological disturbance than the normal population but do not differ from each other. Furthermore, organic and non-organic symptoms occur in the same proportion in compensation and non-compensation patients [6]. Finally, the evidence shows unequivocally that patients with accident-caused disabilities tend not to return to work after litigation proceedings, regardless of outcome; that is, the patient is not 'cured by a verdict' [12]. The evidence, taken together, presents a strong case against the prevailing view of the patients. who receives compensation as a neurotic or a malingerer. The problem appears to be far more complex. It underscores our ignorance of the multitude of subtle psychological and physical factors that contribute to continuing pain and disability after seemingly minor injuries.

The contention that compensation cases report more severe levels of pain than non-compensation cases has been refuted by Mendelson's study [13]. which used the McGill Pain Questionnaire (MPQ). However, it has been argued [2] that the MPQ fails to take into account the true relative intensity of verbal descriptors since the rank-order scoring system favoured by Melzack [9] loses the precise intensity of the 
scale values obtained by Melzack and Torgerson [11]. This is clear when we consider the fact that the words 'throbbing' and 'vicious' receive a rank value of 4 , but have scale values of 2.68 and 4.26 respectively, indicating that the latter descriptor implies much more pain intensity than the former. This loss of information may mask differences which actually exist and may account for Mendelson's failure to find differences between compensation and non-compensation patients.

The purpose of the present study is to compare the MPQ scores of compensation and non-compensation patients by using a simple computational procedure which is based on scale values and corrects for the loss of information when rank values are used. At the same time we examined the scores of these patients on the Minnesota Multiphasic Personality Inventory (MMPI) and other relevant variables.

\section{Methods}

\section{Subjects}

The subjects were 81 patients ( 34 male; 47 female; mean age 43.3 years) suffering chronic low-back pain, and 64 patients ( 22 male; 42 female; mean age 41.9 years) with musculoskeletal pain (predominantly leg, upper-back and shoulder pain). All patients had suffered pain for at least 6 months without effective relief from any of the standard forms of therapy and were referred to the Pain Clinic at the Montreal General Hospital. Among the low-back patients, 27 were on compensation and 54 were not. In the musculoskeletal group, 15 were on compensation and 49 were not.

\section{Procedure}

All subjects were referred to the Pain Clinic by their physicians. On their initial visit, they underwent a standard interview which was structured by means of the McGill Pain Assessment Questionnaire [9] and usually lasted 1-2 h. This was followed by the administration of the MMPI. The data were entered into the computer for later analysis. The data in the present study are based on consecutive patients seen in the clinic between the years 1978 and 1982.

\section{Statistical procedures}

To correct for the loss of information that results from using rank rather than scale values to score the MPQ [11], we have developed an alternate weighted-rank method. The rank scores are rescaled by multiplying the rank of each descriptor within a category by one of twenty weights. The 20 weights were derived by the following formula:

$$
\mathbf{W}_{\mathrm{i}}=\sum_{\mathrm{j}=1}^{\mathbf{n}} \mathrm{S}_{\mathrm{ij}} / \sum_{\mathrm{j}=1}^{\mathbf{n}} \mathbf{R}_{\mathrm{ij}}
$$

where $W_{i}$ is the weighted correction factor for category $i$ ( $i$ ranges from 1 to 20 ), $S_{i}$ is the mean intensity scale value of the doctors' and patients' ratings of the $j^{\text {th }}$ 
TABI.EI

SAMPLE MPQ RESPONSES AND SCORING; USING THE WFIGHTED-RANK METHOD)

The rank score of each descriptor chosen by the patient is multiplied by the weight $\left(W_{i}\right)$ for that category to obtain the corresponding weighted-rank score. These icores are summed as usual to form the PRI-S. PRI-A. PRI-E. PRI-M and PRI-T.

\begin{tabular}{|c|c|c|c|c|c|}
\hline $\begin{array}{l}\mathrm{MPQ} \\
\text { aategory }\end{array}$ & $\begin{array}{l}\text { Weight } \\
\left(W_{1}\right)\end{array}$ & $\begin{array}{l}\text { Descriptor } \\
\text { chosen }\end{array}$ & & $\begin{array}{l}\text { Rank } \\
\text { score }\end{array}$ & $\begin{array}{c}\text { Weighted-rank } \\
\text { score }\end{array}$ \\
\hline 1 & 0.69 & Pulsing & & 3 & 2.07 \\
\hline 2 & 1.38 & & & 1) & 0.00 \\
\hline 3 & 0.93 & Stabbing & & 4 & 3.72 \\
\hline 4 & 1.59 & Sharp & & 1 & 1.59 \\
\hline 5 & 0.81 & & & 0 & 0.001 \\
\hline h & 1.19 & Wrenching & & 3 & 3.57 \\
\hline 7 & 1.28 & Hot & & 1 & 1.28 \\
\hline 8 & 0.70 & Smarting & & 3 & 2.1 \\
\hline 9 & 0.72 & Aching & & 4 & $2.8 x$ \\
\hline \multirow[t]{2}{*}{10} & 0.95 & Tender & & 1 & 0.95 \\
\hline & & & PRI-S = & 20 & 18.16 \\
\hline 11 & 1.74 & Exhausting & & 2 & 3.48 \\
\hline 12 & 2.22 & Sickening & & 1 & 2.22 \\
\hline 13 & 1.87 & Frightful & & 2 & 3.74 \\
\hline 14 & 1.32 & Vicious & & 4 & $5.2 \mathrm{x}$ \\
\hline \multirow[t]{2}{*}{15} & 2.33 & Wretched & & 1 & 2.3 .3 \\
\hline & & & PRI-A = & 10 & 17.05 \\
\hline \multirow[t]{2}{*}{16} & 1.01 & Intense & & 4 & $4.1) 4$ \\
\hline & & & PRI-E = & 4 & 4.114 \\
\hline 17 & 1.22 & - & & 0 & 0.60 \\
\hline 18 & 0.82 & Numb & & 2 & 1.64 \\
\hline 19 & 1.0 & Cool & & 1 & 1.0 \\
\hline \multirow[t]{3}{*}{20} & 1.15 & Agonizing & & 3 & 3.54 \\
\hline & & & $P R I-M=$ & 6 & 6.04 \\
\hline & & & PRI- $\mathrm{T}=$ & 40 & 45.34 \\
\hline
\end{tabular}

descriptor in category $i$, and $R_{i j}$ is the corresponding rank of the $\mathrm{j}^{\mathrm{th}}$ descriptor in category $i$. For category 1 , the formula yields $W_{1}=(1.65+2.05+2.43+2.62+2.73$ $+2.98) /(1+2+3+4+5+6)=0.69$.

The weights for the 20 categories are presented in Table I, along with sample MPQ choices and a demonstration of the weighted-rank scoring method. Category 19 does not appear in the Melzack-Torgerson paper [11] and was therefore given a weight of 1.0 .

To assess how well the weighted-rank and rank values of the MPQ descriptors approximate their original intensity scale values [11], the MPQ pain scores for the 2 patient subgroups were separately submitted to one-way, repeated measurements multivariate analyses of variance using the 3 scoring methods (scale, weighted-rank, and rank) as the repeated measurements factor, and the 4 pain rating indexes 
(PRI-S, PRI-A, PRI-E, and PRI-M) as the dependent variables. Separate univariate ANOVAs were then computed, and for each of the 4 dependent variables, 2 orthogonal null contrasts (the linear and quadratic components) were evaluated across the cell means of the $3 \mathrm{MPQ}$ scoring methods. Because of the linear dependence of the MPQ total pain rating index (PRI-T) on the other PRIs (i.e. PRI-S + PRI-A + PRI-E + PRI-M = PRI-T) it was not possible to include the PRI-T in the multivariate ANOVA. Instead we submitted the PRI-Ts to a univariate, one-way ANOVA using the 3 scoring methods as the repeated measures factor, and then evaluated the linear and quadratic components across the cell means.

The linear component describes a statistical comparison between the mean scale value and the mean weighted-rank value. The quadratic component contrasts the sum of the mean scale and mean weighted-rank values with twice the mean rank value. A statistically non-significant linear component would demonstrate that the weighted-rank method provides an equivalent alternative measure to the scale values, and a statistically significant quadratic component would indicate that the rank approximation to the scale values results in a PRI that is either too large or too small. This pattern of findings would clearly favour the use of the weighted-rank method of scoring the MPQ over the rank method for a more accurate quantitative assessment of a patient's pain.

\section{Results}

\section{Correction by weighted ranks}

Table II contains the mean scale, weighted-rank, and rank values of the PRI-S, $-A,-E,-M$, and $-T$ for the two diagnostic groups. Also shown are the results of the linear and quadratic contrasts evaluating the 3 scoring methods. It can be seen that the pattern of results is the same for patients with low-back and musculoskeletal pain. The multivariate test of Wilks' lambda by Rao's approximate $F$ was highly significant for both groups $(F(8,73)=106.94, P<0.00001 ; F(8,56)=75.86$, $P<0.00001$, respectively). Non-significant linear components and significant quadratic components were found for the PRI-S, -A and -M. The same pattern was found with the univariate ANOVAs of the PRI-T scores (Table II). These findings indicate that, for the PRI-S, - A, -M and -T, the weighted-rank method produces values that are statistically equivalent to the scale values and hence preferable to the rank approximations which depart significantly in either direction from the scale values.

An examination of the statistical contrasts across the means of the PRI-E for both patient groups yielded non-significant linear and quadratic components. Thus, for the PRI-E the rank and weighted-rank scoring methods both approximate the intensity scale values equally well.

Compensation us. non-compensation

In an attempt to distinguish between compensation and non-compensation patients, we entered the following 10 variables into a separate stepwise discriminant 
TABLE II

MEAN SCALE, WEIGHTED-RANK AND RANK VALUES OF THE PAIN RATING INDEXES (PRI) FOR PATIENTS WITH LOW-BACK PAIN AND MUSCULOSKELETAL PAIN

The major PRI classes are sensory (S). affective (A), evaluative (E), miscellaneous (M), and istal (T).

\begin{tabular}{|c|c|c|c|c|c|c|c|}
\hline & $\begin{array}{l}\text { Mean scale } \\
\text { values }\end{array}$ & $\begin{array}{l}\text { Mean weighted- } \\
\text { rank values }\end{array}$ & $\begin{array}{l}\text { Mean rank } \\
\text { values }\end{array}$ & $F_{i+1}^{*}$ & $P$ & $F_{4 u i: 1}^{*}$ & $P$ \\
\hline \multicolumn{8}{|c|}{ Low -hack pain $(\mathrm{N}=81)$} \\
\hline PRI-S & 16.9 & 17.0 & 18.2 & 0.14 & NS & 55.26 & 0.00001 \\
\hline PRI-A & 7.9 & 7.6 & 4.4 & 2.00 & NS & 163.97 & 0.00001 \\
\hline PRI-E: & 2.9 & 3.0 & 2.9 & 0.90 & NS & 0.09 & $\mathrm{NS}$ \\
\hline PRI-M & 6.7 & 6.5 & 6.1 & 1.96 & NS & 55.09 & 0.00001 \\
\hline PRI-T & 34.4 & 34.1 & 31.6 & 0.93 & NS & 74.61 & 0.00001 \\
\hline \multicolumn{8}{|c|}{ Musculoskeletal pain $(\mathrm{N}=64)$} \\
\hline PRI-S & 16.5 & 16.2 & 17.4 & 2.29 & NS & 32.16 & 0.00001 \\
\hline PRI-A & 6.3 & 6.3 & 3.7 & 0.01 & NS & 99.44 & 0.00001 \\
\hline PRI-E. & 2.9 & 2.9 & 2.9 & 0.01 & NS & 1.16 & NS \\
\hline PRI-M & 6.5 & 6.7 & 6.2 & 1.32 & NS & 27.10 & 0.00001 \\
\hline PRI-T & 32.2 & 32.1 & 30.2 & 0.16 & NS & 42.03 & 0.00001 \\
\hline
\end{tabular}

* $d f=(1,80)$ for low-back pain group.

$d f=(1,63)$ for musculoskeletal pain group.

function analysis for each patient group: (1) the total number of consultants sought prior to the initial intake interview, (2) the chronicity of the patient's illness in years, (3) the number of hours slept each night, (4) the PRI-S, (5) PRI-A, (6) PRI-E, (7) PRI-M scored according to the weighted-rank method, and the raw scores from the MMPI (8) depression (D), (9) hypochondriasis (Hs), and (10) hysteria (Hy) scales. The linear dependence of PRI-T on the other PRIs precluded its inclusion in the discriminant analysis as a discriminating variable. We then re-ran the same stepwise discriminant analysis a second time using the PRI-S, PRI-A, PRI-E, and PRI-M scored by the rank method to provide comparisons with the above results produced by using the weighted-rank PRIs. In the following analyses, discriminating variables have been defined as those whose contribution to the discriminant functions resulted in a significant $(P<0.05)$ (a) $F$ ratio to enter the equation, (b) partial $F$ once entered in the equation as well as at subsequent steps, and (c) increase in Rao's $V$.

Low-back pain. The results of the discriminant analysis using weighted ranks (Table III) revealed that the PRI-A discriminated significantly between compensation and non-compensation patients; patients who receive compensation have significantly lower affective pain scores than those who do not $(F(1,69)=3.91$, $P<0.05$ ). In contrast, when the rank values of the PRIs are used, the PRI-A fails to discriminate between the two groups $(F(1,69)=2.97, P<0.09)$.

Because our sample of compensation patients was predominantly male and our non-compensation predominantly female, we compared the PRI-A for males and females. There was no evidence of an affective response bias on the basis of gender $(t(79)=1.48, P=0.14)$. Thus the significantly lower affective pain scores obtained 
TABLE III

MEAN VALUES OBTAINED BY COMPENSATION AND NON-COMPENSATION PATIENTS ON THE PRI INDEXES OF THE McGILL PAIN QUESTIONNAIRE, THE MMPI, AND OTHER VARIABLES

\begin{tabular}{lccccc}
\hline & \multicolumn{2}{l}{ Low-back pain } & & \multicolumn{2}{c}{ Musculoskeletal pain } \\
\cline { 2 - 3 } \cline { 5 - 6 } & Comp. & Non-comp. & & Comp. & Non-comp. \\
\hline PRI-S & 17.1 & 17.8 & 8.9 & 18.2 & 15.4 \\
PRI-A & $6.0^{*}$ & 3.1 & 5.2 & 6.9 \\
PRI-E & 2.7 & 7.0 & $2.2^{*}$ & 3.2 \\
PRI-M & 6.4 & 36.8 & 6.9 & 6.6 \\
PRI-T ${ }^{* *}$ & 32.2 & 29.0 & 32.5 & 32.1 \\
MMPI-D & 26.4 & 22.9 & 23.6 & 28.3 \\
MMPI-Hs & 23.0 & 31.1 & 20.2 & 21.7 \\
MMPI-Hy & 29.9 & & 26.3 & 29.9 \\
No. of Consultants & 3.9 & 4.5 & $2.0^{*}$ & 3.5 \\
Chronicity of Pain & 5.3 & 6.0 & & 2.7 & 6.0 \\
Hours Sleep & 6.3 & 6.3 & 6.2 & 6.7 \\
\hline
\end{tabular}

* Comp. vs. non-comp., $P<0.05$.

** The PRI-T values were not included in the discriminant function analysis - see text.

by compensation patients do not appear to be an artifact due to the patient's gender.

Table IV shows the MPQ adjectives chosen by $30 \%$ or more of the patients with low-back pain. Two features of these data are noteworthy. The first is the remarkable consistency with which low-back pain patients describe their pain - regardless of whether or not they receive financial compensation for their illness. With the exception of the word 'cramping,' every descriptor chosen by $30 \%$ or more of the compensation patients is also chosen by $30 \%$ or more of the non-compensation patients (although the latter group chose additional words). The second feature is the comparatively smaller percentage of compensation patients that chose the affective descriptors. Whereas 97\% of non-compensation patients describe their pain as 'exhausting' or 'tiring,' these words are chosen by $77 \%$ of compensation patients. Furthermore, $41 \%$ of non-compensation patients consider their pain as 'sickening' whereas only $15 \%$ of compensation patients chose this descriptor.

Musculoskeletal pain. Two of the 10 variables discriminated significantly between compensation and non-compensation patients with musculoskeletal pain. Compared with non-compensation patients, compensation patients, on the average, sought the opinion of fewer consultants and subjectively evaluated the overall intensity (PRI-E) of their pain as significantly lower $(F(2,55)=8.68, P<0.0005)$. The number of consultants and the PRI-E are not influenced by the gender of the patients ( $t$ $(62)=1.42, P=0.16$ and $t(62)=1.47, P=0.15$, respectively).

The stepwise discriminant analysis using the PRI rank values produced the same results; the number of consultants and the PRI-E were both lower for patients receiving financial compensation and contributed significantly to discriminating between the groups $(F(2,55)=8.68, P<0.0005)$. 
TABLE: IV

DESCRIPTORS FROM THE MCGILL PAIN QUESTIONNAIRE CHOSEN BY 30\% OR MORE OF COMPENSATION AND NON-COMPENSATION PATIFNTS

\begin{tabular}{|c|c|c|c|}
\hline & Descriptors & Comp. (\%) & Non-comp. (要) \\
\hline \multicolumn{4}{|l|}{ Lam-back pain } \\
\hline Sensory & $\begin{array}{l}\text { Throbbing } \\
\text { Shooting } \\
\text { Stabbing } \\
\text { Sharp } \\
\text { Cramping } \\
\text { Pulling } \\
\text { Burning } \\
\text { Tingling } \\
\text { Aching } \\
\text { Tender }\end{array}$ & $\begin{array}{l}46 \\
58 \\
46 \\
54 \\
35 \\
38 \\
- \\
31 \\
6.5 \\
.\end{array}$ & $\begin{array}{r}37 \\
44 \\
38 \\
56 \\
- \\
30 \\
35 \\
30 \\
50 \\
37\end{array}$ \\
\hline Affective & $\begin{array}{l}\text { Tiring } \\
\text { Exhausting } \\
\text { Sickening }\end{array}$ & $\begin{array}{r}31 \\
46 \\
-\end{array}$ & $\begin{array}{l}41 \\
56 \\
41\end{array}$ \\
\hline Evaluative & Miserable & 35 & 35 \\
\hline Miscellaneous & $\begin{array}{l}\text { Numb } \\
\text { Nagging }\end{array}$ & $\begin{array}{r}42 \\
-\end{array}$ & $\begin{array}{l}31 \\
37\end{array}$ \\
\hline Musculoskeletal & & & \\
\hline Sensory & $\begin{array}{l}\text { Throbbing } \\
\text { Shooting } \\
\text { Stabbing } \\
\text { Sharp } \\
\text { Gnawing } \\
\text { Pulling } \\
\text { Burning } \\
\text { Stinging } \\
\text { Aching } \\
\text { Tender }\end{array}$ & $\begin{array}{l}53 \\
47 \\
60 \\
80 \\
33 \\
33 \\
53 \\
60 \\
53 \\
67\end{array}$ & $\begin{array}{r}- \\
40 \\
56 \\
- \\
31 \\
40 \\
\cdots \\
46 \\
38\end{array}$ \\
\hline Affective & $\begin{array}{l}\text { Tiring } \\
\text { Exhausting }\end{array}$ & $\begin{array}{l}33 \\
53\end{array}$ & $\begin{array}{l}31 \\
48\end{array}$ \\
\hline Evaluative & $\begin{array}{l}\text { Annoying } \\
\text { Unbearable }\end{array}$ & $\begin{array}{r}53 \\
-\end{array}$ & 31 \\
\hline Miscellaneous & $\begin{array}{l}\text { Piercing } \\
\text { Nagging }\end{array}$ & $\begin{array}{l}60 \\
33\end{array}$ & $\begin{array}{r}35 \\
-\end{array}$ \\
\hline
\end{tabular}

A more detailed examination of the MPQ words chosen by these groups can be found in Table IV. Here, as with the low-back pain patients, the consistency with which patients describe their pain is evident. Descriptors chosen by $30 \%$ or more of the non-compensation patients were also chosen by $30 \%$ or more of compensation patients, with the exception of the evaluative descriptor 'unbearable' $(31 \%)$. It is 
interesting that compensation patients chose all words the non-compensation patients chose, in addition to others, yet $53 \%$ of them evaluated their pain as 'annoying' while $31 \%$ of non-compensation patients selected the word 'unbearable.'

\section{Discussion}

The results show convincingly that patients who receive compensation do not report higher levels of pain than patients who do not receive compensation. In fact, patients without compensation have significantly higher scores on the affective (low-back pain) or evaluative (musculoskeletal pain) dimension of the MPQ, although there are no differences between compensation and non-compensation patients in the sensory and miscellaneous scores or in the total pain rating index (PRI-T). The direction of the scores is perhaps not surprising since the non-compensation patients probably had greater financial worries which may be reflected in the higher affective and evaluative scores. In any case the absence of significant differences in the sensory dimension and in the overall total pain scores fully corroborates the conclusion by Mendelson [13], Pelz and Merskey [14] and Leavitt et al. [6] that patients on compensation do not exaggerate their pain compared to patients without compensation.

Not only are the average pain intensities comparable in compensation and non-compensation patients, but the patterns of pain descriptors chosen by compensation and non-compensation patients are remarkably similar. This is true for both low-back and musculoskeletal pain. These data on the subjective qualities of the pain indicate that patients on compensation feel the pain they say they do and are not exaggerating it. The complexity of the verbal descriptor patterns rules out the possibility that the compensation patients were simply reporting descriptors they overheard from patients with 'real' pain.

The results obtained with the MMPI also corroborate the conclusions by Pelz and Merskey [14] using the Symptom Check List-90 and the Levine-Pilowsky Depression Questionnaire, and by Mendelson [13] using the Zung Depression Scale, the Spielberger State-Trait Anxiety Inventory, the Eysenck Personality Inventory and the Hostility and Direction of Hostility Questionnaire that compensation patients do not differ from non-compensation patients in emotional disturbance. In these studies, both groups, which suffered comparable levels of pain, had higher scores than the normal population on depression, anxiety and neuroticism but did not differ from each other. The present study also found heightened scores on the MMPI compared to the normal population, in depression, hysteria and hypochondriasis but, unlike an earlier study using the MMPI [17], there were no differences between compensation and non-compensation patients. Within the musculoskeletal pain group, the larger number of consultations by non-compensation patients is perhaps not surprising since patients receiving no compensation would reasonably be expected to be more concerned about financial problems and, therefore, more actively engaged in seeking a resolution of their disability and pain. This interpretation is consistent with the higher MPQ evaluative scores by the non-compensation patients. 
Taken together, the results indicate that the phrase 'compensation neurosis' is an unwarranted, biased diagnosis. Not only are the disability and pain not 'cured by a verdict [12] but compensation patients do not exaggerate their pain or show evidence of neurosis or other psychopathological symptoms greater than those seen in pain patients without compensation.

The results obtained with the procedure of correction by weighted ranks indicates that the power of the MPQ can be enhanced. Normally, the rank-value procedure appears to be sufficiently sensitive. However, greater sensitivity and accuracy seem to be achieved by the correction. This simple procedure provides scores that more closely approximate the original Melzack and Torgerson [11] scale values than do the unweighted rank values. Although the sensitivity of the MPQ is enhanced by only a relatively small amount, it may be important when differences between groups are nearly significant but fail to reach normally accepted levels of statistical significance. This was clearly illustrated in the patients with low-back pain. The weighted-rank method revealed that compensation patients have significantly lower affective scores than non-compensation patients, whereas the rank method did not.

It is evident from our results and those of others [6,13,14] that compensation often does not play a significant causative role in chronic pain - a conclusion which runs counter to the prevailing ideas $[17,18,21,22]$. Patients on compensation, as we noted in the Introduction, are role-cast as sly, devious neurotics and malingerers who are faking their pain to win or maintain comfortable financial compensation for the rest of their lives. Recent evidence indicates that this is not the typical case. Rather, it is important to examine each individual patient, and not lump all cases together under a single label. Brena and Chapman [1] have made an excellent start in this direction by proposing that all pain patients be considered according to a defined set of physical and psychological criteria so that 4 distinct groups are distinguished from one another. However, even within these groups it is important to recognize the individuality of each patient, who has a unique psychological and medical history. We believe that the recent evidence merits a re-examination of the role of compensation in chronic pain.

We conceive of the person who receives compensation to be primarily the victim of an accident who tries to cope with the resulting disability, pain, loss of income, and disruption of patterns of day-to-day life. As a victim, he deserves the kind of psychological counselling that is now commonly advocated for victims of disasters such as floods or earthquakes $[3,4,15]$. The sudden disruption in the person's normal working pattern as well as in his customary role in the family and community would be expected to produce grief, sadness and bereavement over genuine losses. Accidents, whether large or small, underscore our sense of vulnerability [8]. Even such 'minor' losses which occur after a mugging or a robbery in one's home may produce long-lasting psychological effects [15]. An accident that results in prolonged disability and pain has no less an impact on a person's psychological and physical well-being.

These patients need the best available psychological counselling and medical attention to problems that are often subtle and highly complex. Livingston [7] dealt extensively with such cases in his book on Pain Mechanisms and reported that 
compensation patients who failed to respond to traditional forms of therapy were sometimes cured if the physician recognized that abnormal sympathetic nervous system activity may persist indefinitely after a brief injury, or that trigger spots may develop at the site of even a relatively minor injury. Major procedures such as cordotomies may fail but simple ones such as trigger-point injections may produce sudden, remarkable recovery and a subsequent return to work $[7,16,19,20]$.

Compensation is not a cause of pain, though it is often referred to that way. It is one of multiple factors that interact to produce the nerve-impulse patterns that give rise to pain [10]. To select a single factor as the sole cause represents a failure to recognize the complexity of pain. This does not mean that malingerers or neurotics do not exist. It suggests instead that they may be relatively rare and that unfortunate patients have been misdiagnosed, mistreated and allowed to suffer under the shroud of unfair labels instead of receiving appropriate therapy.

\section{Acknowledgements}

We are grateful to Dr. Paul Taenzer for his assistance.

This study was supported by Grant A7891 from the Natural Sciences and Engineering Research Council of Canada.

\section{References}

1 Brena, S.F. and Chapman, S.L., Pain and litigation. In: P.D. Wall and R. Melzack (Eds.), Textbook of Pain, Churchill-Livingstone, Edinburgh, 1984, pp. 832-839.

2 Charter, R.A. and Nehemkis, A.M., The language of pain intensity and complexity: new methods of scoring the McGill Pain Questionnaire, Percept. Motor Skills, 56 (1983) 519-537.

3 Everstine, D.S. and Everstine, L., People in Crises: Strategic Therapeutic Interventions, Brunner/Mazel, New York, 1983.

4 Howard, H.J., Resnik, H.L.P. and Parad, L.G. (Eds.), Emergency and Disaster Management, The Charles Press, Bowie, MD, 1976.

5 Kennedy, F., The mind of the injured worker: its effect on disability periods, Compens. Med., 1 (1946) 19-24.

6 Leavitt, F., Garron, D.C., McNeill, T.W. and Whisler, W.W., Organic status, psychological disturbance, and pain report characteristics in low-back pain patients on compensation, Spine, 7 (1982) 398-402.

7 Livingston, W.K., Pain Mechanisms, Plenum Press, New York, 1976.

8 McCloud, B., In the wake of disaster, Psychol. Today, 18 (1984) 54-57.

9 Melzack, R., The McGill Pain Questionnaire: major properties and scoring methods, Pain, 1 (1975) 277-299.

10 Melzack, R. and Loeser, J.D., Phantom body pain in paraplegics: evidence for a central "pattern generating mechanism' for pain, Pain, 4 (1978) 195-210.

11 Melzack, R. and Torgerson, W.S., On the language of pain, Anesthesiology, 34 (1971) 50-59.

12 Mendelson, G., Not 'cured by a verdict:' effect of legal settlement on compensation claimants, Med. J. Aust., 2 (1982) 132-134.

13 Mendelson, G., Compensation, pain complaints, and psychological disturbance, Pain, 20 (1984) 169-177.

14 Pelz, M. and Merskey, H., A description of the psychological effects of chronic painful lesions, Pain, 14 (1982) 293-301. 